\title{
Intra-cluster knowledge exchange and frequency of product innovation in a digital cluster
}

\author{
Nasiru Taura and Dragana Radicic \\ Accepted for publication in Journal of Small Business Management \\ DOI: $10.1111 /$ jsbm.12479
}

\begin{abstract}
We investigate how intra-cluster knowledge exchange affects the frequency of product innovation. Based on self-administered survey data of digital SMEs from Bournemouth and Poole regions of England, this study shows that digital firms that sustain both temporary and prolonged relationships with outbound employees have a higher probability of introducing frequent product innovation. Moreover, while cognitive proximity and the use of external knowledge providers increase the probability of frequent product innovation, geographical proximity reduces it. Our findings suggest that managers of young digital firms with limited resources in peripheral regions should 'act near' before reaching out.
\end{abstract}

\section{Introduction}

This study explores how intra-cluster knowledge exchange affects the frequency of product innovation in digital small and medium-sized enterprises (SMEs) located in a peripheral region. Frequent product innovation ${ }^{1}$, otherwise referred to as continuous innovation, is often associated with durable goods, mainly in digital firms (Chen 2012; Thomas 2011). These durable goods are often supported by an infrastructure of a digital ecosystem of computers, digital cameras, mobile phones, cloud broadband, internet, chips programming languages, as well as operating systems (Chen 2012; Paulson et al. 2002; Sussan and Acs 2017). Within a regional cluster, such digital entrepreneurial ecosystem and its infrastructure continuously evolves (Passiante, Elia, and Massari 2003; Sussan and Acs 2017), due to the nature of the digital goods, whereby the physical obsolescence is often slower than technological obsolescence. That is, when new upgrades are available, the old products still remain functional (Chen 2012).

\footnotetext{
${ }^{1}$ In this study, the frequency of product innovation is defined as the occurrences of the frequency of product innovation at certain time intervals - monthly, quarterly, biannually or annually.
} 
The innovation literature suggests that SMEs innovate differently than do large firms because of differences in resources. The main disadvantage of SMEs in this respect is associated with limited financial and human resources. To compensate the limited availability of resources, SMEs open up their innovation process and explore external knowledge sources. In this respect, SMEs are further constrained regarding the breadth and depth of their knowledge search (Teirlinck 2018). But, at the same time, SMEs should use a broader set of external knowledge sources, given their limited internal resources (Radicic and Pugh 2017). Thus, taking into account a greater need to use external knowledge in SME innovation activities, led us to pose the main question of this study: If the ubiquitous nature of clustered digital firms allows them to access and share knowledge, why do some digital firms innovate more frequently than others?

We are particularly interested in intra-cluster knowledge exchange induced by staff mobility, cognitive proximity, spatial (geographical) proximity, and links with knowledge providers (e.g. universities, R\&D centres, and science parks). Accordingly, we infer that, to increase the frequency of product innovation, cluster firms need to intensify knowledge exchange. While frequent product innovation is pertinent to large, high-tech companies, such as Apple and Google, little is known with regards to the frequency of product innovation in small digital firms in the context of cluster settings. Consequently, the first contribution of the study is that we identify specific intra-cluster knowledge exchange types which, if managed strategically, could improve the frequency of product innovation in digital SMEs. This is consistent with the knowledge-based theory of clusters (Maskell 2001; Malmberg and Maskell 2002). Its primary focus is on inter-firm knowledge exchange, which occurs through frequent interactions among cluster firms. ${ }^{2}$ In turn, frequent interactions facilitate inter-firm trust and institutional norms of cooperation, which contribute to the effectiveness of knowledge exchange (Arikan 2009; Malmberg and Power 2005). Furthermore, following the social network theory, knowledge exchange arises due to the social context and connectedness within a cluster, and, we argue, could yield a particular outcome of a frequent product innovation.

The second contribution stems from our focus on knowledge intensive digital firms as product innovation is more likely to be frequent in knowledge intensive business services (KIBS) or embedded in the knowledge-based networked economy (KBNE) (Musolesi and Huiban 2010; Passiante, Elia, and Massari 2003). The role of knowledge-intensive business

\footnotetext{
${ }^{2}$ The channels through which knowledge exchange takes place are numerous, from vertical and horizontal formal and informal cooperation to research consortia.
} 
services, as producers of innovation and new technology, has recently been given consideration (Musolesi and Huiban 2010; Passiante et al. 2003; Teirlinck 2018). Moreover, in relation to peripheral regions, we take into account an unprecedented growth of IT and proliferation of digital connectedness in the periphery instead of the centre, with view to making contribution to 'peripheral entrepreneurialism' and regional learning (DeMartino, Reid, and Zygliodopolous 2006; Julien 2007; Rae 2017).

Finally, we analyse a unique dataset of digital SMEs, specifically gathered for this study. The surveyed firms are located in Bournemouth and Poole digital cluster in the South West of England. According to the Tech Nation report, the cluster experienced the highest number of new venture creations in 2014 (over 200\% growth), making the region the fastest growing digital hub in the UK, even ahead of London. In 2016, the Tech Nation reported that not only was Bournemouth and Poole recognised as the fastest growing digital cluster, but also it hosts the fastest growing firms (26 per cent, based on the headcount). The cluster comprises of firms specialising mainly in digital marketing and advertising, e-commerce, games development and publishing, content and media production, web building, and UI and UX design. It is a constellation of digital products and services involving "the intensive use of advanced technologies, specialised skills, and professional knowledge" (Miozzo and Grimshaw 2006, p.1).

Our empirical findings suggest that the likelihood of frequent product innovation increases when firms sustain relationships with outbound employees, search for innovation from firms with a similar knowledge base and share knowledge with knowledge providers (e.g. universities, R\&D centres, and science parks). With respect to the theoretical implications, this study offers a conceptual framework for investigating the frequency of product innovation, by combining insights from the knowledge-based view of the firm and the social network theory. From the practical perspective, both spatial and non-spatial dimensions should be considered in exploring knowledge exchange (Hansen 2015). Our findings point out that non-spatial knowledge dimensions could be more relevant for knowledge exchange than a spatial dimension for SMEs in digital clusters. In other words, knowledge exchange is more determined by the socio-relational context than it is by the presence of the technical infrastructures (Bahlmann and Huysman 2008). Consequently, managers in small digital firms, located in peripheral regions, should particularly focus on non-spatial dimensions of knowledge exchange. This corroborates recent findings in Hansen (2015) and Teirlinck (2018), whereby social proximity is recognised as a driving force for knowledge exchange in innovation. Regarding policy implications, our findings indicate that regional governments 
should design policies to foster knowledge exchange among small digital firms in peripheral regions.

The remainder of the study is organized as follows. Next section defines frequent product innovation and discusses why frequent product innovation is beneficial to small digital firms. The "Theoretical background" section reviews underlying theoretical frameworks, followed by the hypotheses development. The "Methodology" section reviews the data, empirical strategy and the variables used in the model. The "Results" section presents the results of the empirical analysis. The "Discussion" section relates empirical findings with the formulated hypothesis, as well as discusses the limitations of the study. The final section provides some concluding remarks.

\section{Frequency of Product Innovation}

Product innovation in our survey questionnaire is defined as the market introduction of a new or significantly improved good or service with respect to its capabilities, user friendliness, components or sub-systems. Thus, it encompasses any type of product innovation, regardless of its degree of innovativeness and whether it is an 'original' product or a 'copycat'. 3 For conceptual clarity, it is important to distinguish between closely-related concepts of i) the speed of product innovation, ii) the rate of product innovation and iii) its frequency. Innovation speed refers to time elapsed from the first spark of ideas to final implementation of the innovation, including activities such as initial development, concept building, and commercialisation (Kessler and Chakrabarti 1996). The rate of product innovation is defined as "the average distance travelled up the product ladder per period, which is the product of the size of innovation and the frequency of innovation" (Horowitz and Lai 1996, p. 785). Earlier models focused exclusively on either speed or rate, with little or no attention to frequency of product innovation (Horowitz and Lai 1996; Kesseler and Chackrabarti 1996). Frequency is referred to as the average 'number' of product innovations per period (Horowitz and Lai 1996, p.785). Instead of counting the average number of product innovations, the definition adopted in this study focuses on the occurrences of the frequency of product innovation at certain regular intervals (monthly, quarterly, six monthly, yearly).

\footnotetext{
${ }^{3}$ Although the quality of product innovations may significantly differ, our definition focuses on the measurable attributes of product innovations in line with the Community Innovation Survey (CIS) questionnaire. Given the quantifiable nature of our study, we focus on the measurable attributes, thus avoiding subjectivities associated with 'value creation' versus 'value capture' (Bowman and Ambrosini 2002), linked to the perceived quality of the product innovations throughout the whole process of innovation (from idea generation to market introduction).
} 
Before establishing a link between different dimensions of knowledge exchange and the frequency of product innovation, it is important to discuss potential benefits and costs of frequent product innovation. Regarding the former, frequent product innovations could be beneficial to firms, regardless of their success in the market place. If product innovation is successfully commercialised, it increases firms' sales and revenue from new products (Wang and Wang 2012). Even if product innovation is not successfully commercialised, it provides an opportunity for firms to 'learn from failure' and 'fail forward' subsequently, which reduces uncertainty and improves variety of opportunities for future innovative product launches, perhaps even more frequently thereafter (McGrath 1999).

Following Robson et al. (2012), firms that accumulate and leverage human capital are more like to 'try' innovation and introduce it. Consistent with this argument, we pontificate that digital firms, which accumulated human capital from prior experiences of frequent product innovations, leading to the development of firms' portfolio of innovative products could leverage future product innovations with a higher likelihood of 'trying' and 'introducing' innovations more frequently (Robson et al. 2012).

Moreover, frequent product innovation helps towards preservation, reproduction, or duplication of selected activities by repetition (Aldrich and Reuf 2006; Gluckler 2007). This has been referred to elsewhere as cross-generational improvability, implying that products are cross-generational compatible, such that if consumers upgrade old software, the functionality of the system still remains unaffected (Chen 2012). For example, users of Nintendo could use Nintendo Wii console to play games developed for Nintendo GameCube, with only limited utility, such as motion sensing controllers. In so doing, frequent product innovation across generations could lead to cumulative value, until obsolescence (Chen 2012).

In contrast, a potential detrimental effect of frequent product innovation, especially for resource-constrained small digital firms, is concerned with the 'attention allocation problem' (Ocasio, 1997), identified in the context of the attention-based view of the firm. Namely, the process of innovation (from idea creation, concept building, prototyping, to commercialisation) necessarily requires a certain level of managerial attention and commitment, which can be problematic, particularly in small firms. In addition, small digital firms would also have to deal with the difficult task of balancing internal and external acquisition of knowledge (Grimpe and Kaiser 2010). In doing so, there is a possibility of certain product innovations 'crowding out' other innovation activities or increase the likelihood that the resource base of the firm suffers from dilution. 
In addition to the "management attention problem", another issue with frequent product innovation could be free riding due to opportunistic behaviour (Adner and Kapoor 2010) and tendency of other cluster firms to imitate product innovation of the focal firm (i.e. copycat products). However, rather than using patents and other costly mechanisms for protecting intellectual property rights (IPRs), small digital firms are more likely to protect their innovations through industrial secrecy and speed to market (Becheikh et al. 2006; Leiponen and Byma 2009). Nonetheless, despite potential negative effects of frequent product innovation, we posit that its benefits should outweigh costs arising from spreading managerial attention thinly or using informal intellectual property strategies.

\section{Theoretical background}

Our theoretical arguments are derived from two theoretical frameworks. The first framework is the knowledge-based view of a cluster, which regards knowledge as a fundamental resource for sustainability, growth, and dynamism of a cluster system (Acs et al. 2017; Miller and Acs 2017; Sussan and Acs 2017). Therefore, innovative firms tend to engage in more than just internal use of knowledge and the exchange of pre-existing knowledge (Bell and Albu 1999). Instead, they engage in external knowledge exchange with other firms, as well as with knowledge providers (Doran, Declan, and Eoin 2012; Lasagni 2012; Taura and Watkins 2014). We extend this argument by suggesting that knowledge exchange not only influences the propensity to innovate, but also its frequency.

The second framework is the social network theory, in which knowledge exchange is embedded in the social context (Bahlmann and Huysman 2008). In other words, the characteristics of social relationships and the resulting networks can affect knowledge absorption and exchange. These knowledge networks consist of different nodes of firms that mutually create and exchange knowledge through social interactions (Díez-Vial and MontoroSánchez 2014). In turn, firms increasingly recognise that their social network is the locus of innovation activities (Nambisan and Sawhney 2011; Pittaway et al. 2004; Powell et al. 1996).

Digital innovation in clusters, supported by advanced communication infrastructure, have challenged the traditional organisational boundaries by stripping out barriers of communication and permitting firms to be more responsive to their environment and specialised in virtual spaces (Passiante et al. 2003). The "virtualness perspective" has given digital firms a new form of strategic advantage, as reinforced by geographical proximity and 
organisational proximity of the clustered firms (Findikoglu and Watson-Manheim 2015; Passiante et al. 2003; Presutti, Boari, and Majocchi 2011). In this context, we argue that digital firms that take the advantage of various dimensions of proximity, transcending spatial boundaries, are more likely to engage in product innovation more frequently. ${ }^{4}$

Within a cluster, both knowledge exchange (spillover) effects and competition effects exist. This relates to the notion of the "knowledge exchange climate" in clusters, recently introduced by Vestal and Danneels (2018). The "knowledge exchange climate", reflecting different values and norms concerning knowledge exchange in a cluster, can follow one of two opposing logics: a market-based and a community-based. A market-based logic prevails when cluster firms are characterised by an uneven level of inventive activities. In this situation, firms will be less prone to knowledge exchange, given that the risk of non-reciprocity in knowledge exchange is higher. In contrast, a community-based logic applies to those clusters in which firms have a similar level of inventive activities. In such a knowledge exchange climate, the likelihood of knowledge exchange is higher, as firms are more open and willing to share valuable knowledge. Our argument, based on the dyadic nature of the "knowledge exchange climate" is that, in a cluster of digital SMEs such as ours, the level of innovative activities among firms will be similar, which means that the community-based logic will prevail. In other words, digital SMEs will be motivated to search and explore opportunities for knowledge exchange with other intra-cluster firms. This will, in turn, lead to frequent introduction of product innovation.

\section{Hypotheses development}

In this section, we develop hypotheses in relation to specific types of intra-cluster knowledge exchange, which are in the focus of the study. First, we consider the influence of temporary and prolonged outbound mobility on the frequency of product innovation. Then we explore ways in which cognitive proximity might affect the frequency. Next we discuss the role of spatial proximity. Finally, we look at the links with external providers and how they might influence frequent product innovation. By investigating cognitive and social dimensions, as well as spatial proximity, our study is consistent with Hansen's (2015) argument on the

\footnotetext{
${ }^{4}$ Variability exists with regards to how firms frequently innovate even within the same industry. In the digital industry in the period from 2009 to 2011, Samsung launched a series of Galaxy phones much more frequently than iPhones, as Apple insists on developing software and hardware on its own, while the Galaxy phones runs on Google's Android operating systems (Chen 2012).
} 
necessity of addressing both spatial and non-spatial dimensions of knowledge exchange in clusters.

Frequency of product innovations and intra-cluster transfer of knowledge induced by employee mobility

Following the social network theory, social networks play a critical role in temporary collaborations or project-based working, which is pertinent to many service industries (Grabher 2002). Outbound mobility may generate knowledge exchange is through interpersonal communication channels between the firm hiring the employee and the old firm (Corredoira and Rosenkopf 2010). For instance, Agrawal, Cockburn, and McHale (2006) note that 'enduring social relationships' between outbound inventors and their old colleagues increase the likelihood of knowledge spillovers in the old firm. However, most empirical studies on labour mobility and innovation have been done in the context of patenting activities. if, we argue, social relationships positively affect patenting activities, then a similar effect should occur in the case of the frequency of innovation. Namely, concerning the innovation process, patents are considered as an intermediate innovation outcome, while product innovation is a final outcome. A positive correlation between outbound mobility and patenting then could be extended to the final outcome of the innovation process. Thus, taking into consideration the importance of social relations, we posit that the impact of employee mobility on frequent product innovations is dependent on both physical and social mobility of outbound employees (Di Domenico, Daniel, and Nunan 2014). Employees are nowadays a part of a large web of digital natives, whose digital footprints are costly to destroy once established. It is not uncommon for outbound employees to be active participants in predecessors' firms digital space, such as blogs, forums, open innovation platforms, mobility events, etc. Firms that are quick at terminating and restricting access to all forms of relationships with outbound employees, including social relations through digital and social media spaces, are less likely to co-create/co-produce with them and benefit from knowledge exchange (Corredoira and Rosenkopf 2010). In contrast, other firms strategically co-produce innovative ideas with outbound employees by treating them as "gone but not lost" (Somaya et al. 2008). Such firms tend to value the relational ties that were developed between the outbound employees and fellow workers who worked together in the old firm (Corredoira and Rosenkopf 2010).

Most outbound employees leave behind a footprint of uncompleted/work-in-progress (WIP) projects. The unintended consequences of terminating all relational ties with outbound 
employees are costly, since the uncompleted projects left behind risks becoming redundant. However, it is possible that the knowledge and skills of a new inbound employee assigned to work on a product or a project left behind by an outbound employee could create a (recombinant) spark (Antonella 2006), leading to new directions for an existing innovative idea. While this might be good for the firm in the long run, it could, however, be a digression from the chain of frequent production innovation that could arise had uncompleted projects been executed through cooperation with outbound employees.

As the process through which a WIP product (or project) left behind comes to fruition, could take longer without the cooperation of the outbound employee, then we infer that a relational tie with outbound employees could be positively associated with the frequency of product innovations. While it is likely that product innovations could be positively associated with temporary outbound mobility, we suspect that the probability for frequent product innovations becomes less likely in the case of prolonged relationships with outbound employees. This might be because outbound employees would be in a state of liminality ('inbetween-ness') only temporarily, after which point they transition fully to the new organisation by reconciling their spatial, temporal, and emotional tensions or, more specifically, between their new physical, relative to previous digital spaces (Di Domenico, Daniel, and Nunan 2014). Thus, we formulate the following.

H1: Digital firms that temporarily sustain transfer of knowledge with outbound employees have a higher probability of introducing frequent product innovations.

H2: Prolonged transfer of knowledge with outbound employees leads to a lower probability of introducing frequent product innovations.

Frequency of product innovations and intra-cluster knowledge exchange induced by cognitive proximity

Cognitive proximity is a relational attribute which underpins how firms commonly perceive, interpret, understand, and evaluate the world around them (Nooteboom 1999; 2000; Weick 1979). It has a tendency to heighten exchange of the same (related) knowledge between firms and subsequently improved performances (Nooteboom 2004). This is consistent with the social network theory, which posits that firms are more likely to exchange knowledge with similar firms, given that they can benefit most from these exchanges (Díez-Vial and Montoro- 
Sánchez 2014). The relatedness of the knowledge base is regarded as one of the prerequisites for frequent innovation activities in cluster firms (Arikan 2009).

Clusters that have organised themselves in such a way to create opportunities for firms to engaged in activities leading to acquiring, accumulating and processing of the same (related) knowledge, are more likely to be dynamic (Bell and Albu 1999). Scholars have suggested that clusters interested in improving their innovativeness should frequently undertake 'mapping of knowledge base', as knowledge changes over time (Bell and Albu 1999; Mytelka 2000). Hence, a cluster of firms with unrelated (dissimilar) knowledge base would not stimulate continuous flow of innovative activities (Giuliani, 2005). Following this line of argument, we note that a certain level of cognitive proximity through a network is required to enable firms to effectively assimilate, absorb, process and exchange knowledge (Nooteboom 1999; 2000). Moreover, cognitive proximity could induce firms to engage in more effective processes of searching and gathering knowledge, thus leading to faster decision-making cycles relative to new product development (Cyert, Simon, and Trow 1956). Consequently, firms in a cluster might experience a higher probability of knowledge exchange induced by cognitive proximity, leading to a frequent introduction of product innovation.

The peripheral context, pertinent to seaside towns of Bournemouth and Poole, can induce the development of deeper social relationships and connections leading to entrepreneurial discoveries and innovations linked to availability of 'time' and 'space' (Rae 2017). The experience of separation from the centre might induce individuals and firms to look inwards (Rae 2017), prompting them to act within a certain cognitive proximity. In so doing, digital firms, prompted by a peripheral context in which fewer cognitive connections and traffics exist, are more likely to engage in deeper and long-lasting (sustained) relationships when exchanging knowledge and ideas (Rae 2017). In such atmosphere of sustained knowledge exchange, as well as creative associations and learning between firms, we speculate a higher likelihood of engagement in frequent product innovations. Thus, we formulate:

H3: Digital firms that sustain the exchange of the same type of knowledge have a higher probability of introducing frequent product innovations.

Frequency of product innovations and intra-cluster exchange of knowledge induced by spatial (geographical) proximity 
Spatial proximity refers to the physical distance between economic actors (Doran, Declan and Eoin 2012). Given that our focus is on a digital cluster, it means that firms mainly work and collaborate in digital spaces (the so-called cyberspace). In so doing, scholars argue for the limited role of geography in the names of 'end of geography', 'distance decay', 'spaceless city' etc. (Graham and Marvin 1996; Pawley 1995). A closer look, however, reveals that a virtual (digital) space is better understood within the context of co-evolving systems, where both 'electronic' and 'territorial' spaces co-produces and shapes each other, while a regional systemic restructuring takes place (Clarke, Holt, and Brundel 2014; Graham 1998; Mitchell 1995).

This process leads to the development of new technology or a hub of digital artefact, based on continuous recombinations of social and spatial dimensions, leading to a new hybrid of socio-technical 'actor-networks' (Graham 1998). Internet geography research reveals interesting patterns of knowledge creation on the internet relative to geography globally (Graham 1998). According to Agarwal, Audretsch, and Sarkar (2007), knowledge-exchange processes can have two distinct, but related aspects - local and cosmopolitan. A local aspect of cluster knowledge exchange system is associated with its capacity to collectively create and exchange knowledge locally within clusters, leading to spatially-induced innovation milieu (Arikan 2009; Julien 2007; Doran, Declan and Eoin 2012). Knowledge exchange is more likely to take place within shorter geographical distances, primarily as a result of frequent face-toface interactions and a potential for trust building (Doran, Declan and Eoin 2012; Gordon and McCann 2005). The downside is that sometimes this could result in 'trust lock in' (i.e. trusting only local players) (Zahra, Yavuz, and Ucbasaran 2006), which limits how variety enters a system, eventually leading to downward performance spiral and decline of innovativeness (Boschma 2005; Martin and Sunley 2006). On the other hand, a cosmopolitan aspect is associated with knowledge exchange with agents located outside clusters (Arikan 2009). Intensive knowledge exchanges with geographically distant agents could stimulate innovation (Bathelt, Malmberg, and Maskell 2004), and is vital for a longer-term regional dynamism (Bell and Albu 1999; Powell and Grodal 2006). Moreover, firms relying on distant external sources of knowledge could have their innovative frequency negatively affected due to transaction costs (Bell et al. 2009).

External knowledge is costly as it encompasses relationships with external agents, such as customers, suppliers, competitors and support agencies outside the cluster (Doran, Declan and Eoin 2012). In addition to transaction costs, firms that reach out to external sources are bound to incur 're-orientation costs' (DeMartino et al. 2006). Re-orientation cost is the cost of 
changes and realignment on existing interactions, which arises when firms in a cluster reach outside their home region to gain access to resources and develop capabilities (DeMartino et al. 2006; Pounder and John 1996). In contrast, increased face-to-face interaction with regional players, instead of reaching outside home region for resources, is likely be less costly since it avoids re-orientation costs (DeMartino et al. 2006). Furthermore, spatial proximity increases the probability of social interactions during, e.g. "TechSocial" events (Rae, 2017). In turn, knowledge exchange, through frequent face-to-face contacts and social events, increases the likelihood of frequent product innovations. This is a consequence of trust and willingness to share knowledge among firms, developed through personal and frequent interactions (Adner and Kapoor 2010; Doran, Declan and Eoin 2012). Thus, we formulate the following hypothesis.

H4: Digital firms that engage in knowledge exchange only with firms in the local region have a higher probability of introducing frequent product innovations.

Frequency of product innovations and intra-cluster exchange of knowledge induced by external knowledge providers

As noted in the introduction, SMEs are hampered with limited human and financial resources in their innovation activities. To compensate for the limited internal resources, small firms need to open up their innovation processes and explore linkages, not just with other firms, but also with external knowledge providers. The latter provides firms with the broadest knowledge base and the greatest ease of access, as well as a low risk of knowledge leakage and opportunistic behaviour (Un et al. 2010). Appropriability issues and mistrust are least likely to occur in public-private partnerships, relative to the inter-firm knowledge exchange.

Prior empirical evidence suggests that linkages to external knowledge providers, such as universities, science parks, and R\&D centres, improves firms' innovativeness (McCormick and Maalu 2011; Taura 2012). Especially relevant for our study, firms within a cluster that reaches out to external knowledge providers could innovative more frequently (Musolesi and Huiban 2010; Taura and Watkins 2014). Reaching out to knowledge providers could shorten the lengthy processes of internal production of knowledge (Musolesi and Huiban 2012). This trend is likely to continue, due to increasing tendency for knowledge providers to engage in open innovation through mutual partnerships with regional entrepreneurs. Networking with 
external knowledge providers could stimulate entrepreneurial activities, leading to local “entrepreneurial milieu” (Julien 2007). In line with previous arguments, we posit the following.

H5: Digital firms that use external knowledge providers (i.e. universities, $R \& D$ centres, and science parks), have a higher probability of introducing frequent product innovations.

Based on the overall discussion above, Figure 1 shows the conceptual model on the determinants of frequent product innovations in small firms, operating in a digital peripheral cluster. The focus of the study is on firm characteristics capturing intra-cluster knowledge exchange, in particular, outbound mobility, cognitive proximity, geographical proximity, and links with external knowledge providers. The framework also encompasses firm heterogeneity with respect to size, age, resources for product innovation, and share of employees with tertiary degree.

\section{Figure 1. The Conceptual Framework}

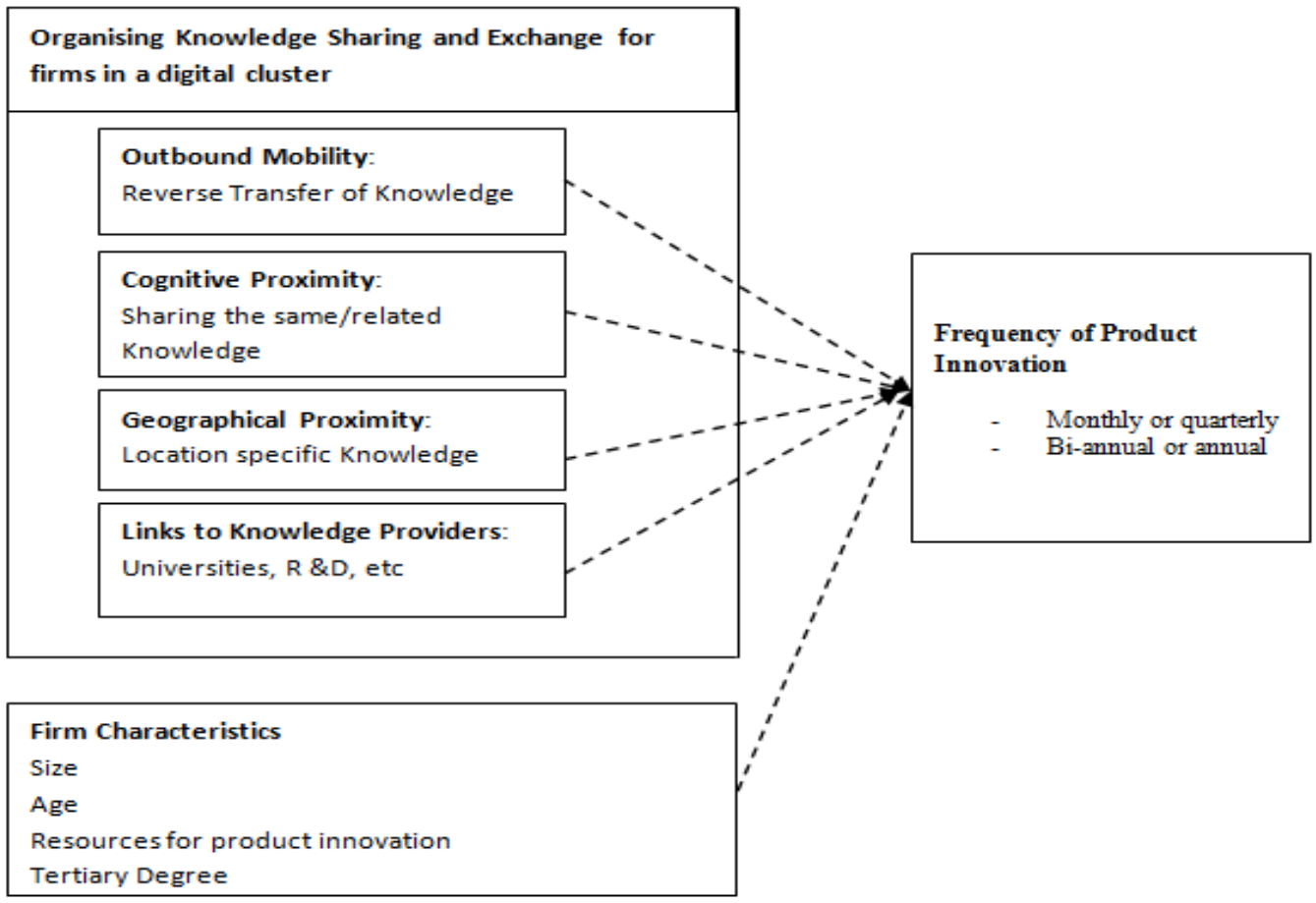

\section{Methodology}

\section{Data}


This study is based on a survey conducted within the South West of England, specifically Bournemouth and Poole. The questionnaire was administered between May and August 2016, covering the period 2014-2016. The sample is limited to digital SMEs as our aim is to contribute to understanding of the frequency of product innovation in this context. The questionnaire was administered randomly using both online and face-to-face methods. The survey was circulated to 505 digital firms.

Firms that engage in a frequent product innovation might tend to respond to the survey, which would imply that the higher likelihood of introducing frequent product innovation could result in an upward bias in our empirical results. To tackle this potential response bias, our survey was conducted using random sampling, but because the survey was not mandatory, firms that engage in a frequent product innovation could have been over-represented in our sample. Thus, we note that the empirical results might be upward bias.

Of the 505 firms contacted, a total of 304 firms responded, representing a response rate of 60.2 per cent. Due to missing values, effective sample is reduced to 244 responses. As data are self-reported, common method variance, arising from the measurement method, could bias the estimates due to systematic measurement error (Podsakoff and Organ 1986). To check the internal validity of our data, we conducted Harmon's one-factor test (Podsakoff and Organ 1986). The test encompasses an explanatory factor analysis of all independent variables by using unrotated principle component factor analysis. When the common method bias is unlikely to occur, the first unrotated factor (i.e. the factor accounting for the largest share of the variance of the independent variables) should account for less than 50 per cent of the total variation in the other explanatory variables within the model. In our model, the first factor accounts for around 21.5 per cent of total variation, which suggests that common method bias raises no great concern in our model.

Out of 244 firms, 37 firms (15 per cent) reported not to frequently introduce product innovation, 90 firms (37 per cent) reported to have introduced product innovation either monthly or quarterly, while 117 firms (48 per cent) reported either bi-annual or annual introduction of product innovation. Table 1 presents summary statistics and variable description. Regarding maintaining relationships with outbound employees, almost two thirds of firms (64 per cent) reported to maintain temporary relationships, while slightly less than one third of firms (32 per cent) maintain prolonged relationships (up to a year) with outbound employees. With respect to external knowledge exchange, slightly less than one third of firms 
(32 per cent) search for innovation only from firms with presumably the same knowledge and the same share of firms exchange knowledge only with organisations in the region.

Only 13 per cent of digital firms collaborate with external knowledge providers (universities, R\&D centres, and science parks). Concerning firm characteristics, slightly less than one third (32 per cent) of firms are young firms (younger than five years), while two thirds of firms (66 per cent) are micro firms with less than ten employees. On average, firms have between $25 \%$ and $49 \%$ of employees with a tertiary degree and less than one third (29 per cent) reported to have had leading or above average innovation capabilities within the industry associated with product innovation in 2014.

Table 1. Variable description and summary statistics

\begin{tabular}{|c|c|c|}
\hline Variable name & Variable description & $\begin{array}{c}\text { Mean } \\
\text { (standard } \\
\text { deviation) }\end{array}$ \\
\hline \multicolumn{3}{|l|}{ Variables of interest } \\
\hline Outbound - temporary & $\begin{array}{l}\mathrm{DV}=1 \text { if a firm responded "Yes" to the question "We } \\
\text { temporarily (up to } 6 \text { months) allow for relationships to } \\
\text { flourish with outgoing employees"; zero otherwise }\end{array}$ & $\begin{array}{c}0.639 \\
(0.481)\end{array}$ \\
\hline Outbound - prolonged & $\begin{array}{l}\text { DV=1 if a firm responded "Yes" to the question "We } \\
\text { allow for prolonged (up to } 1 \text { year) relationships with } \\
\text { former employees who moved to other firms or } \\
\text { organisations"; zero otherwise }\end{array}$ & $\begin{array}{c}0.316 \\
(0.466)\end{array}$ \\
\hline Cognitive proximity & $\begin{array}{l}\mathrm{DV}=1 \text { if a firm responded "Yes" to the question "We } \\
\text { search for innovations only from firms with presumably } \\
\text { the same knowledge"; zero otherwise }\end{array}$ & $\begin{array}{c}0.316 \\
(0.466)\end{array}$ \\
\hline Geographical proximity & $\begin{array}{l}\mathrm{DV}=1 \text { if a firm responded "Yes" to the question "We tend } \\
\text { to share and exchange knowledge only with recognised } \\
\text { organisations in the local region"; zero otherwise }\end{array}$ & $\begin{array}{c}0.316 \\
(0.466)\end{array}$ \\
\hline $\begin{array}{l}\text { External knowledge } \\
\text { providers }\end{array}$ & $\begin{array}{l}\mathrm{DV}=1 \text { if a firm responded "Yes" to the question "We } \\
\text { reach out to external sources of knowledge, such as } \\
\text { universities, R\&D centres, and science parks, for purposes } \\
\text { of collaborating to develop digital innovations"; zero } \\
\text { otherwise }\end{array}$ & $\begin{array}{c}0.131 \\
(0.338)\end{array}$ \\
\hline \multicolumn{3}{|l|}{ Control variables } \\
\hline Young & $\mathrm{DV}=1$ if a firm is younger than five years; zero otherwise & $\begin{array}{c}0.316 \\
(0.466)\end{array}$ \\
\hline Micro firms & $\begin{array}{l}\text { DV=1 if a firm has less than ten employees; zero } \\
\text { otherwise }\end{array}$ & $\begin{array}{c}0.656 \\
(0.476)\end{array}$ \\
\hline Tertiary degree & $\begin{array}{l}\text { Categorical variable }=0 \text { if a firm has no employees with a } \\
\text { tertiary degree; }=1 \text { if a firm has between } 1 \% \text { and } 24 \% \text { of } \\
\text { employees with a tertiary degree; }=2 \text { if a firm has between } \\
25 \% \text { and } 49 \% \text { of employees with a tertiary degree; }=3 \text { if a } \\
\text { firm has between } 50 \% \text { and } 74 \% \text { of employees with a } \\
\text { tertiary degree; }=4 \text { if a firm has more than } 74 \% \text { of } \\
\text { employees with a tertiary degree }\end{array}$ & $\begin{array}{c}2.168 \\
(1.483)\end{array}$ \\
\hline $\begin{array}{l}\text { Resources for product } \\
\text { innovation }\end{array}$ & $\begin{array}{l}\mathrm{DV}=1 \text { if a firm responded with "Leading" or "Above } \\
\text { average" to the question: "How would you judge your }\end{array}$ & $\begin{array}{c}0.291 \\
(0.455)\end{array}$ \\
\hline
\end{tabular}




\begin{tabular}{|l|l|l|}
\hline & $\begin{array}{l}\text { firm's innovation capabilities within your industry in the } \\
\text { past (2014), regarding product innovation?"; = 0 if a firm } \\
\text { responded "Average" or "Lagging" }\end{array}$ & \\
\hline
\end{tabular}

\section{Measures}

We construct our model following the Knowledge Exchange Function approach applied to KIBS (Musolesi and Huiban 2010). The main issue is that knowledge is not observable, especially if it is socially embedded in a cluster. Thus, instead of direct measurement, we used proxies for different types of intra-cluster knowledge exchange. For the measurement of knowledge exchange, as well as frequent product innovation, we rely on the perception of managers, given their critical role in charting out firms' social embeddedness by actively forming and reproducing their networks over time in ways that yields innovative outcomes (Jack and Anderson 2002; Nambisan and Sawhney 2011; Pittaway et al. 2004; Powell et al. 1996). In the context of our digital cluster, managers are uniquely positioned to possess the knowledge of how their digital firms belong to certain networks, leading to the accumulated social capital (Hulsink et al. 2009; Walker, Kogut and Shan 1997). Although relying on the managers perceptions, accounts, and interpretation could limit the value of our findings, due to cognitive and psychological bias (Van de Ven and Hudson 1985), it would be quite difficult to capture objective measures of knowledge exchange.

As noted earlier, our definition of product innovation is "the market introduction of a new or significantly improved good or service with respect to its capabilities, user friendliness, components or sub-systems". One of the novelties of our survey is that it captures frequency of product innovation, which is in not included in the Community Innovation Survey (CIS) questionnaire. Frequency of product innovation $(F P I)$ is modelled as a function of intra-cluster knowledge exchanges (IKE) and firm-specific characteristics $Z$.

$$
F P I=f(I K E, Z)
$$

Intra-cluster knowledge exchanges (IKE) encompass the following five binary variables (see Table 1).

- Outbound_temporary equals to 1 if a firm temporarily (up to 6 months) maintains relations with outbound employees; zero otherwise. 
- Outbound_prolonged equals to 1 if a firm maintains prolonged relationships (up to one year) with outbound employees; zero otherwise.

- Cognitive proximity equals to 1 for those firms that responded "Yes" to the question "We search for innovations only from firms with presumably the same knowledge"; zero otherwise.

- Geographical proximity equals to 1 for those firms that responded "Yes" to the question "We tend to share and exchange knowledge only with recognised organisations in the local region"; zero otherwise.

- External knowledge providers equals to 1 for those firms that responded "Yes" to the question "We reach out to external sources of knowledge, such as universities, R\&D centres, and science parks, for purposes of collaborating to develop digital innovations"; zero otherwise

\section{Controls variables}

Firm-specific characteristics $Z$ include the following four variables.

- Young equals to 1 for firms younger than 5 years, zero otherwise.

- Micro firms equals to firms with less than 10 employees; zero otherwise.

- Tertiary degree is a categorical variable $=0$ if a firm has no employees with a tertiary degree; $=1$ if a firm has between $1 \%$ and $24 \%$ of employees with a tertiary degree; $=2$ if a firm has between $25 \%$ and $49 \%$ of employees with a tertiary degree; $=3$ if a firm has between $50 \%$ and $74 \%$ of employees with a tertiary degree; $=4$ if a firm has more than $74 \%$ of employees with a tertiary degree.

- Resource product innovation is a binary variable equal to 1 if a firm responded with "Leading" or "Above average" to the question: "How would you judge your firm's innovation capabilities within your industry in the past (2014), regarding product innovation?"; = 0 if a firm responded "Average" or "Lagging".

Our survey questionnaire does not include a question on R\&D intensity for the following reasons. SMEs are less likely to conduct formal $R \& D$ than large firms (Ortega-Argiles et al. 2009). It would be quite difficult for survey respondents to evaluate R\&D intensity if their firms do not have a dedicated $R \& D$ department, thus mostly conducting informal $R \& D$ activities, which is pertinent to small firms (Ortega-Argiles et al. 2009; Kleinknecht and Reijnen 1991). Moreover, according to Ortega-Argiles et al. (2009), one of the key 
determinants of innovation activities in firms is their sectoral belonging, i.e. firms operating in high-tech sectors will invest more in innovation activities than firms in traditional sectors. Consequently, given that we focus on a single sector and on SMEs, without taking into account large firms, we can assume that R\&D intensity of SMEs in a digital sector in a peripheral region have a similar R\&D intensity. Moreover, the standard proxies of patents or $R \& D$ expenditure have been criticised as not being appropriate measures to capture the underlying innovation processes embedded in a regional cluster (Peneder 2001; Scott 2006).

Regarding unobserved firm-level characteristics, such as complementary assets and the degree of capital constraints, our independent variable Resources for product innovation controls for "quasi fixed effects" (or initial conditions) (Blundell et al. 1995). These initial conditions control for firms' permanent innovation capabilities reflected in the pre-sample history of innovation output, i.e. firms' innovative capacity with respect to product innovation at the beginning of the period covered by the survey (see also Hagedoorn and Wang 2012; Radicic et al. 2016; Radicic and Pugh 2017). Specification with "quasi fixed effects" is an approach for controlling for otherwise unobserved heterogeneity which, as yet, has not been widely adopted by researchers in the broad field of innovation studies. More importantly, we take into account firms' absorptive capacity by controlling for their past innovative capacity (see e.g. Miotti and Sachwald 2003).

We are unable to control for the varieties of business fields within digital industry. Namely, respondents were offered five categories with respect to the business field: advertising and marketing; e-commerce, web building; games development and publishing; and others. However, the categories were not exclusive, thus, for instance, 12 firms reported to operate in three fields: advertising and marketing, e-commerce, and web building, while 18 firms reported to operate in two fields: advertising and marketing, and e-commerce. In other words, it is not possible to create dummy variables that would represent exclusive business fields as a number of surveyed firms operates in more than one business fields.

Finally, the correlation matrix showing the Pearson correlation coefficients among the independent variables is presented in Appendix Table A2. The correlations are overall weak to moderate (Taylor 1990), suggesting that multicollinearity is unlikely to occur.

\section{Estimation strategy}


A multinomial logit model is used when the dependent variable has more than two categories that are not ordered. The formal model is as follows:

$$
\ln \Omega_{m \mid b}(x)=\ln \frac{\operatorname{Pr}(y=m \mid x)}{\operatorname{Pr}(y=b \mid x)}=x \beta_{m \mid b} \quad \text { for } m=1 \text { to } J
$$

Where $\Omega$ denotes odds, $\operatorname{Pr}$ is the probability, $y$ is the dependent variable, $x$ is the vector of the independent variables, $m$ denotes the outcome of the dependent variable ranging from 1 to $J$, $\ln$ is the natural logarithm, and $b$ is the base category (the reference group) (Long and Freese 2006, p. 175).

The predicted probabilities are computed as follows:

$$
\operatorname{Pr}(y=m \mid x)=\frac{\exp \left(x \beta_{m \mid b}\right)}{\sum_{j=1}^{J} \exp \left(x \beta_{j \mid b}\right)}
$$

In the survey questionnaire, firms were asked whether they introduce product innovation (1) never; (2) monthly; (3) quarterly; (4) biannually; and (5) annually. We first estimated a multinomial logit model with these five categories of the dependent variable and then used the Likelihood Ratio (LR) test to investigate whether they can be combined (i.e. collapsed). The test indicates that the first (product innovation introduced monthly) and the second category (product innovation introduced quarterly) can be combined into one category.

Moreover, the test indicates that the third (product innovation is introduced biannually) and the fourth category (product innovation is introduced annually) can be collapsed into one category. ${ }^{5}$ Consequently, we estimate and report a multinomial logit model with three categories: (1) no frequent innovation (the base category); (2) either monthly or quarterly product innovation; and (3) either biannually or annually product innovation.

Given that outcome 1 is the base category, the probability equation is computed as:

$$
\operatorname{Pr}(y=m \mid x)=\frac{\exp \left(x \beta_{m \mid 1}\right)}{\sum_{j=1}^{J} \exp \left(x \beta_{j \mid 1}\right)}
$$

And we obtain estimates $\hat{\beta}_{2 \mid 1}$ and $\hat{\beta}_{3 \mid 1}$ while $\beta_{1 \mid 1}=0$ (Long and Freese, 2006, p. 175).

Furthermore, we tested the assumption of the independence of irrelevant alternatives (IIA) using both the Hausman test and Small and Hsiao test of IIA. The IIA assumption applied

\footnotetext{
${ }^{5}$ Results are not reported, but are available upon request.
} 
in our model states that, all else being equal, a firm's choice between two alternative outcomes is unaffected by what other choices are available (Cheng and Long 2007). Both tests uniformly indicate that the assumption is not violated in our model. ${ }^{6}$

For a robustness check, we consider estimating the ordered logit model. The underlying assumption of the model is the parallel regression assumption or the proportional odds assumption. This assumption posits that the slope coefficients are identical across all categories of the dependent variable (i.e., all outcomes) (Long and Freese 2001, p. 150). According to Long and Freese (2001, p. 152), this assumption is often violated, while Williams (2006) suggests that common practice is to ignore the violation of the proportional odds assumption and report the estimates of the ordered logit model, which are then incorrect or misleading. For our model, the likelihood ratio test developed by Wolfe and Gould (1998) indicates that the proportional odds assumption can be rejected at the $1 \%$ level. The second test we used is the Wald test (also known as the Brant test, after Brant 1990) indicate that the proportional odds assumption can be rejected (for variables Outbound_temporary, Geographical proximity, Tertiary degree and Resources_product innovation at the 1\% level; for variables Young, Micro firms and Cognitive proximity at the 5\% level). Thus, we do not estimate ordered logit model because the proportional odds assumption is violated. In contrast, the multinomial logit model does not require this assumption (Long and Freese 2001, p. 169).

\section{Results}

Table 2 shows results from the multinomial logit model. To quantitatively interpret the results, we estimated the adjusted risk ratios (ARRs) and adjusted risk differences (ARDs). Because all our variables of interest are binary, we will explain these risk ratios from the perspective of a binary independent variable and the model for a binary outcome (probit or logit). First, we need to define $P_{l}$ and $P_{0}$ (see formulae 4 and 5 below), whereby $P_{l}$ denotes the predicted probability that the dependent variable $y$ is equal to 1 , the variable of interest $x$ is equal to 1 and all other independent variables are equal to their original values. $P_{0}$ is the predicted probability defined in a corresponding way and the only difference relative to $P_{1}$ is that the variable $\mathrm{x}$ has a value of zero. Both predicted probabilities are computed over the whole sample $N$. After both predicted probabilities are computed, we can calculate the ARR as the ratio $P_{1} / P_{0}$ and the ARD as the difference $P_{1}-P_{0}$ (Norton et al. 2013).

\footnotetext{
${ }^{6}$ Results are not reported, but are available upon request.
} 


$$
\begin{aligned}
& P_{1}=\frac{1}{N} \sum_{i=1}^{N} \operatorname{Pr}\left(y_{1}=1 \mid X, x=1\right) \\
& P_{0}=\frac{1}{N} \sum_{i=1}^{N} \operatorname{Pr}\left(y_{1}=1 \mid X, x=0\right)
\end{aligned}
$$

The predicted probabilities for a multinomial logit model are calculated in the same way, except that the model has three outcomes, rather than two, which is the case in probit or logit models. Table 3 shows presents ARRs and ARDs for the model reported in Table 2.

Table 2. Results from the multinomial logit model. Outcome 1 (no frequent product

\begin{tabular}{|c|c|c|}
\hline \multirow[b]{2}{*}{ Variables } & \multicolumn{2}{|c|}{ Frequency of product innovation } \\
\hline & $\begin{array}{c}\text { Monthly or } \\
\text { quarterly } \\
\text { (outcome 2) }\end{array}$ & $\begin{array}{c}\text { Biannually or } \\
\text { annually } \\
\text { (outcome 3) }\end{array}$ \\
\hline \multicolumn{3}{|l|}{ Variables of interest } \\
\hline Outbound - temporary & $\begin{array}{c}1.657 * * * \\
(0.517)\end{array}$ & $\begin{array}{c}0.564 \\
(0.445)\end{array}$ \\
\hline Outbound - prolonged & $\begin{array}{c}0.190 \\
(0.586)\end{array}$ & $\begin{array}{c}0.318 \\
(0.550)\end{array}$ \\
\hline Cognitive proximity & $\begin{array}{c}0.801 \\
(0.553)\end{array}$ & $\begin{array}{l}-0.727 \\
(0.489)\end{array}$ \\
\hline Geographical proximity & $\begin{array}{c}-1.101 * \\
(0.572)\end{array}$ & $\begin{array}{c}0.303 \\
(0.462)\end{array}$ \\
\hline External knowledge providers & $\begin{array}{c}1.091 \\
(0.946)\end{array}$ & $\begin{array}{c}0.995 \\
(0.846)\end{array}$ \\
\hline Control variables & & \\
\hline Young & $\begin{array}{c}1.235^{* *} \\
(0.508)\end{array}$ & $\begin{array}{c}0.475 \\
(0.491)\end{array}$ \\
\hline Micro firms & $\begin{array}{c}1.019^{*} \\
(0.580)\end{array}$ & $\begin{array}{c}-0.289 \\
(0.444)\end{array}$ \\
\hline Tertiary degree & $\begin{array}{c}0.363 * * \\
(0.161)\end{array}$ & $\begin{array}{c}-0.008 \\
(0.143)\end{array}$ \\
\hline Resources_products innovation & $\begin{array}{c}3.038 * * * \\
(0.762)\end{array}$ & $\begin{array}{c}1.746 * * \\
(0.774)\end{array}$ \\
\hline Constant & $\begin{array}{c}-2.843 * * * \\
(0.798)\end{array}$ & $\begin{array}{c}0.663 \\
(0.587)\end{array}$ \\
\hline $\begin{array}{l}\text { Log likelihood } \\
\chi^{2}(20) \\
\text { Pseudo } \mathrm{R}^{2}\end{array}$ & $\begin{array}{c}-200.248 \\
66.47 * * * \\
0.185\end{array}$ & \\
\hline
\end{tabular}
innovation) is the base category. 
Number of observations 244

Notes: Standard errors in parentheses. $* \mathrm{p}<0.01, * * \mathrm{p}<0.05, * * * \mathrm{p}<0$.

Table 3. Adjusted risk ratios (ARRs) and adjusted risk differences (ARDs).

\begin{tabular}{|c|c|c|c|c|}
\hline \multirow{2}{*}{ Variables } & \multicolumn{2}{|c|}{ Monthly or quarterly } & \multicolumn{2}{|c|}{ Biannually or annually } \\
\hline & ARRs & ARDs & ARRs & ARDs \\
\hline \multicolumn{5}{|l|}{ Variables of interest } \\
\hline Outbound_temporary & $\begin{array}{c}1.839 * * * \\
(0.380)\end{array}$ & $\begin{array}{c}0.202 * * * \\
(0.059)\end{array}$ & $\begin{array}{c}0.827 * * * \\
(0.113)\end{array}$ & $\begin{array}{l}-0.095 \\
(0.070)\end{array}$ \\
\hline \multirow[t]{2}{*}{ Outbound_prolonged } & $0.970 * * *$ & -0.011 & $1.089 * * *$ & 0.042 \\
\hline & $(0.164)$ & $(0.062)$ & $(0.160)$ & $(0.073)$ \\
\hline \multirow[t]{2}{*}{ Cognitive proximity } & $1.796 * * *$ & $0.235 * * *$ & $0.543 * * *$ & $-0.258 * * *$ \\
\hline & $(0.269)$ & $(0.062)$ & $(0.097)$ & $(0.064)$ \\
\hline \multirow[t]{2}{*}{ Geographical proximity } & $0.508 * * *$ & $-0.215^{* * *}$ & $1.500 * * *$ & $0.208 * * *$ \\
\hline & $(0.110)$ & $(0.057)$ & $(0.188)$ & $(0.067)$ \\
\hline \multirow[t]{2}{*}{ External knowledge providers } & $1.119 * * *$ & 0.044 & $1.101 * * *$ & 0.048 \\
\hline & $(0.247)$ & $(0.089)$ & $(0.195)$ & $(0.091)$ \\
\hline \multicolumn{5}{|l|}{ Control variables } \\
\hline \multirow[t]{2}{*}{ Young } & $1.478 * * *$ & $0.151 * *$ & $0.855 * * *$ & -0.073 \\
\hline & $(0.226)$ & $(0.060)$ & $(0.128)$ & $(0.068)$ \\
\hline \multirow[t]{2}{*}{ Micro firms } & $1.868 * * *$ & $0.203 * * *$ & $0.676 * * *$ & $-0.197 * * *$ \\
\hline & $(0.420)$ & $(0.062)$ & $(0.091)$ & $(0.070)$ \\
\hline \multicolumn{5}{|l|}{ Tertiary degree } \\
\hline (2) vs (1) & $0.930 * * *$ & -0.012 & $1.213 * * *$ & $0.062 * * *$ \\
\hline & $(0.095)$ & $(0.017)$ & $(0.079)$ & $(0.018)$ \\
\hline (3) vs (2) & $1.187 * * *$ & $0.066 * * *$ & $0.893 * * *$ & $-0.053 * *$ \\
\hline & $(0.061)$ & $(0.020)$ & $(0.043)$ & $(0.021)$ \\
\hline (4) vs (3) & $1.162 * * *$ & $0.068 * * *$ & $0.878 * * *$ & $-0.054 * * *$ \\
\hline & $(0.046)$ & $(0.021)$ & $(0.050)$ & $(0.020)$ \\
\hline \multirow[t]{2}{*}{ Resources_product innovation } & $1.995 * * *$ & $0.282 * * *$ & $0.786 * * *$ & -0.110 \\
\hline & $(0.304)$ & $(0.064)$ & $(0.124)$ & $(0.068)$ \\
\hline
\end{tabular}

Notes: Standard errors in parentheses. ${ }^{* * *} \mathrm{p}<0.01,{ }^{* *} \mathrm{p}<0.05, * \mathrm{p}<0.10$. For the variable tertiary degree: (1) a firm has between $1 \%$ and $24 \%$ of employees with a tertiary degree, (2) if a firm has between $25 \%$ and $49 \%$ of employees with a tertiary degree, (3) a firm has between $50 \%$ and $74 \%$ of employees with a tertiary degree, (4) a firm has more than $74 \%$ of employees with a tertiary degree.

The interpretations of ARDs and ARRs from Table 3 are as follows. Regarding our variables of interest measuring the length of relationship with outbound employees, empirical results provide support for hypothesis $H 1$, that is, firms that maintain temporary relationships with outbound employees are 1.839 times more likely to introduce product innovation frequently (monthly or quarterly) than firms which have no relationships with outgoing employees $(A R R=1.839)$. In terms of absolute difference, firms having temporary relations with outbound employees are 20.2 p.p. more likely to introduce product innovation every month or every quarter $(\mathrm{ARD}=0.202)$. In contrast, for less frequent introduction of product 
innovation (every six months or a year), we found that firms maintaining temporary relations with outbound employees are 1.173 times less likely (or $17.3 \%$, where $0.173=1-0.827$ ) to introduce product innovation every six months or a year than their counterparts ( $A R R=0.827)$. However, the absolute difference of 9.5 percentage points (p.p.) is not statistically significant at any conventional level (ARR=-0.095).

Besides estimating the impact of temporary relationships with outbound employees on the frequency of innovation, our models also include binary indicator for firms that have prolonged relationships with former employees. Here, the pattern is opposite to the one found for the impact of temporary relations on the frequency of product innovation. Accordingly, maintaining prolonged relationships with outbound employees reduces the probability of a more frequent introduction of product innovation (monthly or quarterly), while it increases the probability of a less frequent introduction of product innovation (biannually or annually). Concerning risk ratios, firms maintaining prolonged relationships with outbound employees are 1.03 times less likely (or 3\%, where $0.03=1-0.970$ ) to engage in product innovation on a monthly or quarterly basis, although the absolute difference (ARD=-0.011) is not statistically significant at any conventional level. Conversely, firms having prolonged relationships with outbound employees are 1.089 times more likely (or 8.9\%; $\mathrm{ARR}=1.089$ ) to introduce product innovation every six months or a year, but again, the absolute difference (ARD=0.042) is not statistically significant at any conventional level. These results provide support for hypothesis $H 2$.

Concerning cognitive proximity, empirical findings conform to hypothesis $H 3$. Namely, firms that search for innovation from other firms with a similar knowledge base are 1.796 times more likely $(79.6 \%$ more likely; ARR=1.796) to introduce frequent product innovation on a monthly or quarterly basis than firms which are not restricted to searching innovation only from other firms with a similar knowledge base. Alternatively, firms that search for innovation from other firms with a similar knowledge base introduce a frequent product innovation 23.5 p.p. more often than their counterparts ( $\mathrm{ARD}=0.235)$. In contrast, for the less frequent product innovation, our results suggest that searching for innovation from other firms with a similar knowledge base reduces the probability of engaging in product innovation in longer intervals (biannually or annually). Namely, those firms that use other firms with a similar knowledge base as a source of innovation are 1.457 times less likely (or $45.7 \%$ less likely, where $0.457=1-0.543$ ) to introduce product innovation biannually or annually than their counterparts $(\mathrm{ARR}=0.543)$. With respect to absolute differences, the probability of less 
frequent product innovation is 25.8 p.p. lower for firms that use other firms with a similar knowledge base as a source of innovation than their counterparts $(\mathrm{ARD}=-0.258)$.

A contrasting pattern is found for geographical proximity, i.e. the effects of knowledge exchange only with firms in the local region. Accordingly, firms that exclusively share and exchange knowledge with local firms are 1.492 times less likely (or 49.2\% less likely, where $0.492=1-0.508$ ) to introduce product innovation frequently (i.e. monthly or quarterly) than their counterparts $(A R R=0.508)$. Looking at the absolute differences $(A R D=-0.215)$, firms that exclusively share and exchange knowledge with local firms are 21.5 p.p. less likely to engage in a frequent product innovation, on average. Contrastingly, firms that exclusively share and exchange knowledge with local firms are 1.5 times more likely (or 50\% more likely; $\mathrm{ARR}=1.500$ ) to introduce product innovation on a biannual or annual basis than their counterparts. This relative difference corresponds to a large absolute difference of 20.8 p.p. $(A R D=0.208)$. These results provide partial support for hypothesis $H 4$.

With respect to the indicator of proximity in relation to the use of external knowledge sources (such as universities, R\&D centres, and science parks), empirical results provide support for H5, suggesting that using external knowledge providers increases the probability of product innovation, regardless of the time frame (monthly or quarterly; semi-annually or annually). Even the ARRs are quite similar (1.119 for more frequent and 1.101 for less frequent product innovation). However, the absolute differences are not significant at any conventional level.

In relation to control variables, younger SMEs are 1.478 times more likely (47.8\% more likely; ARR=1.478) to introduce product innovation on a monthly or quarterly basis than their older counterparts, on average. This large relative difference corresponds to a relatively large absolute difference of $15.1 \%$ p.p. ( $\mathrm{ARD}=0.151)$. Concerning biannual or annual engagement in product innovation, our results suggest that younger SMEs are less likely to introduce product innovation than older firms $(\mathrm{ARR}=0.855)$ although the absolute difference is small $(\mathrm{ARD}=-0.073)$ and not statistically significant.

Micro firms with less than 10 employees are 1.868 times more likely $(86.8 \%$ more likely; $A R R=1.868$ ) to introduce product innovation on a monthly or quarterly basis than small and medium-sized firms. In terms of absolute differences, the probability of introducing product innovation on a monthly or quarterly basis is 20.3 p.p. higher for micro firms than for small and medium firms, on average $(\mathrm{ARD}=0.203)$. In relation to less frequent introduction of product innovation, micro firms are 1.324 times less likely (or $32.4 \%$ less likely, where 0.324 $=1-0.676$ ) to introduce product innovation on biannual or annual basis than small and medium 
firms (ARR=0.676). This large relative difference corresponds to the large absolute difference of 19.7 p.p. That is, micro firms introduce product innovation 19.7 p.p. less often than small and medium firms on biannual or annual basis, on average ( $\mathrm{ARD}=-0.197)$.

Given that variable Tertiary degree is categorical (see Table 1), we have calculated the ARRs and ARDs for three cases. Our results suggest that firms with less than $49 \%$ of employees with a tertiary degree (2 vs 1 ) are less likely to introduce product innovation every month or a quarter, while firms with more than $50 \%$ share of employees with a tertiary degree are more likely to frequently introduce product innovation.

Finally, regarding firms' past innovation resources in product innovation within the industry (variable Resources_product innovation), our results indicate that firms that are leading or above average are 1.995 more likely $(\mathrm{ARR}=1.995)$ to introduce product innovation on a monthly or quarterly basis. Correspondingly, the absolute difference is quite large as well $(A R D=0.282)$, suggesting that the probability of a less frequent product innovation is 28.2 p.p. higher for firms with the above-average innovation resources in product innovation. However, the above-average innovation resources reduce the probability of product innovation in a longer period (semi-annual or annual). The ARR of 0.786 indicates that firms with the aboveaverage innovation resources are $21.4 \%$ (or $0.214=1-0.786$ ) less likely to innovate in a longer period, although this risk ratio does not correspond to a significant absolute difference $(A R D=$ $-0.11)$.

\section{Discussion}

The idea that peripheral regions are remote, loosely connected, and marginal (Rae 2017), have undergone fundamental shift, due to digital cluster connectivity, with consequences to regional development and distribution of wealth. This development enabled a complete reconfiguration of how new knowledge is created and shared in virtual spaces, leading to new forms of knowledge commercialisation and pervasiveness of innovation. Peripheral regions are important for stimulating the critical mass of fast-growing firms, which could subsequently lead to local innovation milieu, regional growth hub, and digital entrepreneurial ecosystems (Julien 2007; Susan and Acs 2017).

Our focus on Bournemouth and Poole regions in the South West of England is due to the rebirth of national interest for local regenerative activities of 'seaside towns' in the periphery (Rickey and Houghton 2009). The emergence of one of Britain's fastest growing digital cluster in Bournemouth and Poole has, arguably, contributed towards stabilised conditions and, perhaps, prevent a decline of poorer neighbourhoods in the region. In so doing, 
the peripherality of Bournemouth and Poole has renewed and rejuvenated economic potentials and achieved legitimacy and value, as one of Britain's most active zones of digital start-ups and fast growth innovative firms (Rae 2017).

In this context, we explore our main research question, defined in the introductory section: If the ubiquitous nature of clustered digital firms allows them to access and share knowledge, why do some digital firms innovate more frequently than others?

In answering this question, we identified specific intra-cluster knowledge exchange routines which, if managed strategically, could improve the frequency of product innovations. We focus on intra-cluster transfer of knowledge induced by staff mobility, cognitive proximity, geographical proximity, and by links with external knowledge providers. A tendency for associational behaviour, network cooperation, and civic society might be higher in peripheral regions than in core regions (Putnam 2000). What seaside towns like Bournemouth and Poole in the periphery lack in resources, compared to mainstream digital centres like London or Cambridge, is complemented by availability of 'time' and 'space' (Rae 2017). They act as a seedbed for the emergence of various forms of cooperative relationships (i.e. social capital) leading to the phenomenon of frequent innovations in the cluster. Consequently, digital entrepreneurial activities of the peripheral regions, such as Bournemouth and Poole, are supported by the development of 'social infrastructure' (Flora et al. 1997). In this context, digital events, like Silicon South, exemplify the cooperative (relational) ties among cluster firms. Moreover, Bournemouth and Poole boost the birth of many 'space labs'. For example, Barclays have chosen to open one its first three Eagle labs in the country in the region, ahead of Cambridge and Brighton, offering range of resources such as 3D printers, laser cutters and event spaces for digital start-up freelancers, willing to produce and test prototypes (Slade 2016). Moreover, the Global Group, Creative, Print \& Digital also opened a brand new 24/7 work space at the heart of Bournemouth town centre with vision to attract creative freelancers, tech, media, and digital start-ups to the region (Global Group 2017).

Our findings provide support for hypothesis $H 1$, suggesting that digital firms that sustain temporary relationships with outbound employees have a higher probability of introducing frequent product innovations (on monthly or quarterly basis), while maintaining prolonged relationships results in a lower probability of frequent product innovation, conforming to hypothesis H2. The foundation of these relationships between outbound employees and the focal firm, which provide the flow of ideas, knowledge and practices, is based on the existing contextual 'social infrastructure' (Flora et al. 1997). In relation to Bournemouth and Poole, these findings emphasise that associational behaviour and social 
network cooperation, rich in peripheral regions, could bolster frequent innovative tendencies. Activities specific to the region of Bournemouth and Poole, such as the open Data Lab acknowledged as one of the world's largest open device lab (housing over 450 connected devices free for anyone to test their products), exemplify the role of 'socio-technical infrastructure', which fosters cognitive proximity and knowledge exchange among digital firms.

From the managerial perspective, the above findings could also have implications to the practice of the 'out of contract' employee engagement as a strategic tool for small firms in which the employee movement is quite frequent. Instead of insisting on the long-term retention strategies where it might be impractical, smaller digital firms could focus on outbound employee management as 'gone but not lost' (Somaya et al. 2008). Our finding, therefore, suggest that relational ties that were developed between the mobile employee and fellow workers, who worked together in the old firm, is relevant for firms' innovativeness (Corredoira and Rosenkopf 2010, p.161) and is an underutilised source of knowledge assets for competitiveness and value creation.

With regards to cognitive proximity, we find that $H 3$ is supported for more frequent engagement in product innovation because firms that search for innovation from firms with a similar/the same knowledge base are more likely to introduce frequent product innovation than firms which are not restricted to searching innovation only from firms with a similar knowledge base. Our findings in relation to cognitive proximity point out that, to increase the likelihood of frequent innovations, small digital firms should not only focus on what they know and who they know and the resources they have access to, but also should 'act' on knowledge resources in cognitive proximity. Instead of encouraging firms to reach out to external firms beyond their knowledge base, leading to imbalance between localisation versus globalisation (DeMartino et al. 2006), firms maximise the use of local knowledge resources by 'acting near while thinking far'.

Regarding geographical proximity, our empirical findings provide a partial support to hypothesis $H 4$, given that knowledge exchange with local firms increases a probability of a biannual or annual product innovation, but not of more frequent, monthly or quarterly product innovation. Therefore, our results imply that spatial proximity is less relevant for frequent product innovation. This is consistent with the most recent studies on the role of different knowledge dimensions on knowledge exchange (see Hansen 2015; Teirlinck 2018). These studies report that non-spatial knowledge dimensions are key drivers for knowledge exchange in innovation, and at the same time, substitute geographical proximity. Moreover, and specific 
to the region under investigation, the results might reflect the pattern of certain geographicallyinduced events, such as Bournemouth Silicon Beach festival and the Digital Day Bournemouth. Given that these events are being held annually, it is possible they contribute to knowledge exchange and subsequent introduction of product innovation. If this is indeed the case, our findings provide support for such events being held more often to stimulate such dynamism.

Regarding hypothesis $H 5$ on the influence of knowledge providers on the frequency of product innovation, our empirical evidence provide support for this influence in the case of both more frequent (monthly and quarterly) and less frequent (biannual and annual) product innovation. Therefore, of all the variables of interest, links to knowledge providers uniformly increase the probability of engagement in product innovations, irrespective of the length of time (monthly, quarterly, biannually, and annually). This finding is in line with the literature which suggests that links to knowledge providers improves the likelihood of frequent innovations (Taura and Watkins 2014). Inflow of knowledge from external knowledge providers has been suggested as a 'conduit pipe', which neutralises the tendency for cluster firms to engage in replication and exchange of local knowledge for prolonged period, thus avoiding the trap for repetitive transaction chains and constraints to change (Bell and Albu 1999; Giuliani 2005; Tidd and Bessant 2009). This is relevant, as the previous literature suggests that cluster firms, engaged in repeated transactions over time, develop social bonds, thus making it difficult to switch trading partners or evolve their existing governance structure (Bell et al. 2009; Tidd and Bessant 2009). Moreover, the finding could be associated with the role of the region's universities in the supply of the talent pool which fuels the digital ecosystem in the region. This talent flow into the system has led to the creation of regional critical mass of digital entrepreneurs, as a consequence of which, regional annual events such as the Silicon South are being held. A key attribute Bournemouth and Poole, which facilitates the phenomenon of knowledge exchange, could be traced to the historical development of an enabling environment where creative artists and scientists work harmoniously together. For example, the cluster have been cited as one of the clusters in the UK with highest access to the right talent and sector expertise, originating from the National Centre for Computing and Animation at Bournemouth University (Tech Nation Report 2015).

\section{Limitations and Further Research}

Besides offering novel insights into the impact of knowledge exchange on frequency of product innovation, our study suffers from limitations that can serve as suggestions for future 
research. First, our model might be suffering from the endogeneity problem, in particular reverse causality. Namely, a firm that frequently introduces product innovation might engage in more innovation projects simultaneously, which affects the probability of connecting with outbound employees. Furthermore, a firm that frequently introduces product innovations could be more likely to have a broad network of partners, which affects spatial and non-spatial dimensions of knowledge, and the links with external knowledge providers. However, this issue remains to be addressed in future research, as empirically, we cannot employ the instrumental variable (IV) approach, because of the lack of a valid instrument, nor we can use a panel analysis, given that our dataset is cross-sectional. Second, with regards to the generalisation of our findings, our study focuses on the digital cluster in a peripheral region, which does not allow us to draw any conclusions regarding core regions. Thus, further studies could encompass both types of regions and reveal potential similarities and differences between them with respect to how knowledge exchange affects the frequency of product innovation. Third, our dataset does not contain more than one idem to measure independent variables. For instance, instead of a binary indicator for the use of external knowledge providers, future studies could utilize the Likert scale to measure the importance of using a particular knowledge provider. Moreover, regarding geographical distance, our model does not control for the average distance between cluster-partners because our dataset does not contain this information. Future research that would encompass this measure of the geographical distance would allow for a fine-grained analysis of the effect of geographical proximity on frequency of product innovation. Finally, besides frequency of product innovation, future research might explore how knowledge exchange influences frequency of other types of innovation, such as process innovation and non-technological (organisational and marketing) innovations.

\section{Conclusion}

Drawing from the two theoretical frameworks on knowledge exchange and social networks, we empirically investigate how intra-cluster knowledge exchange affects the likelihood of introducing frequent product innovations. Based on self-administered survey data of 224 digital firms from Bournemouth and Poole, seaside towns located in South West of England, this study offers several insights. First, empirical findings show that digital firms that sustain both temporary and prolonged relationships with outbound employees have a higher probability of introducing product innovations on monthly or quarterly basis. Second, firms searching for innovation from firms with a similar knowledge base are more likely to introduce 
frequent product innovation. Third, digital firms that share knowledge only with firms in the local region have a lower probability of introducing frequent product innovations. Finally, our results indicate that using external knowledge providers increases the probability of frequent product innovation, irrespective of its frequency. Our findings have theoretical implications such that we develop a conceptual framework that suggests the link between knowledge exchange and the frequency of product innovation. With respect to different knowledge dimension, our study contributes to the most recent evidence on the importance of non-spatial dimensions (Hansen 2015; Teirlinck 2018), and their potentially substituting role in relation to geographical dimension. Concerning managerial implications, our findings suggest that managers of small digital firms, located in peripheral regions, should 'act near' before reaching out with respect to non-spatial knowledge dimensions, as well as links with external knowledge providers. Finally, sustained investment in knowledge assets, including knowledge management, knowledge creation, and knowledge leadership, could foster dynamism of peripheral regions (Passiante et al. 2003). Therefore, our findings provide support for regional governments to invest in designing policies to foster knowledge exchange in peripheral, digital clusters. For instance, by incentivising and encouraging local 'tech social' events, regional governments could contribute to the development of social infrastructure, which, in turn, increases the frequency of innovativeness.

\section{References}

Acs, Z.J., and D. B. Audretsch (1988). "Innovation in large and small firms: an empirical analysis," American Economic Review 78(4), 678-690.

Acs, Z.J., E. Stam, D. B. Audretsch, and A. O’Connor (2017). “The lineages of the entrepreneurial ecosystem approach," Small Business Economics 49(1), 1-10.

Adner, R., and R. Kapoor (2010). "Value creation in innovation ecosystems: How the structure of technological interdependence affects firm performance in new technology generation,” Strategic Management Journal 31(3), 306-333.

Agarwal, R., D. Audretsch, and M. B. Sarkar (2007). “The process of creative construction: Knowledge spillovers, entrepreneurship and economic growth," Strategic Entrepreneurship Journal 1(2), 263-286.

Agrawal, A., I. Cockburn, and J. McHale (2006). “Gone but Not Forgotten: Knowledge Flows, Labor Mobility, and Enduring Social Relationships," Journal of Economic Geography 6(5), 571-591. 
Aldrich, H.E., and M.A. Martinez (2001). "Many are called, but few are chosen: An evolutionary perspective for the study of entrepreneurship," Entrepreneurship Theory and Practice 25(4), 41-56.

Arikan, A. T. (2009). "Interfirm knowledge exchanges and knowledge creation capability of clusters," Academy of Management Review 34(4), 658-676.

Armbruster, H., A. Bikfalvib, S. Kinkela, and G. Lay (2008). “Organizational innovation: the challenge of measuring non-technical innovation in large-scale surveys," Technovation 28(10), 644-657.

Bahlmann, M.D, and M.H. Huysman (2008). "The Emergence of a Knowledge-Based View of Clusters and Its Implications for Cluster Governance," The Information Society 24(5), 304-318.

Becheikh, N., R. Landry, and N. Amara (2006). "Lessons From Innovation Empirical Studies In the Manufacturing Sector: A Systematic Review of the Literature From 1993 2003," Technovation 26, 644-664.

Bell, M., and M. Albu (1999). "Knowledge systems and technological dynamism in industrial clusters in developing countries," World Development 27(9), 1715-1734.

Bell, S. J., P. Tracey, and J. B. Heide (2009). “The Organisation of Regional Clusters," Academy of Management Review 34(4), 623-642.

Bocquet, R., O. Brossard, and M. Sabatier (2007). "Complementarities in organizational design and the diffusion of information technologies: an empirical analysis,"Research Policy 36(3), 367-386.

Bowman, C., and V. Ambrosini (2000). "Value Creation versus Value Capture: Towards a Coherent Definition of Value in Strategy," British Journal of Management 11, 1-15.

Blundell R., R. Griffith, and J. Van Reenan (1995). "Dynamic count data models of technological innovation," The Economic Journal 105, 333-344.

Brant, R. (1990). “Assessing Proportionality in the Proportional Odds Model for Ordinal Logistic Regression," Biometrics 46(4), 1171-1178.

Braunerhjelm, P., D. Ding, and P. Thulin (2018). "The knowledge spillover theory of Intrapreneurship," Small Business Economics 51, 1-30.

Breslin, D. (2008). "A review of evolutionary approach to the study of entrepreneurship, " International Journal of Management Reviews 10(4), 399-423.

Burt, R. S. (2000). “The Network Structure of Social Capital,” Research in Organisational Behaviour (22), 345-423. 
Cardon, M.S., J. Wincent, J. Singh, and M. Drnovsek. (2009). "The nature and experience of entrepreneurial passion," Academy of Management Review 34(3), 511-532.

Chatterjee, R., and Y. Sugita (1990). "New product introduction under demand uncertainty in competitive industries," Managerial and Decision Economics 11(1), 1-12.

Chen, Y. (2012). "Innovation frequency of durable complementary goods," Journal of Mathematical Economics 48 (6), 407-421.

Cheng, S., and J. S. Long (2007). "Testing for IIA in the Multinomial Logit Model," Sociological Methods \& Research 35(4), 583-600.

Clarke, J., R. Holt, and R. Brundel (2014). "Re-imagining the growth process: (co)-evolving metaphorical representations of entrepreneurial growth," Entrepreneurship and Regional Development 26(3-4), 234-256.

Corredoira, R., and L. Rosenkopf (2010). "Should auld acquaintance be forgot? The reverse transfer of knowledge through mobility ties," Strategic Management Journal 31(2), $159-181$.

Cyert, R. M., H. A. Simon, and D. B. Trow (1956). "Observation of a Business Decision," Journal of Business 29(4), 237-248.

DeMartino, R., D. M. Reid, and S. C. Zygliodopolous (2006). "Balancing Localisation and Globalisation: Exploring the impact of Firm Internationalisation on a Regional cluster," Entrepreneurship and Regional Development 18(1), 1-24.

Di Domenico, M., E. Daniel, and D. Nunan (2014). "Mental mobility in the digital age: entrepreneurs and the online home-based business," New Technology, Work and Employment 29(3), 266-281.

Díez-Vial, I., and A. Montoro-Sánchez (2014). "Social capital as a driver of local knowledge exchange: a social network analysis," Knowledge Management Research \& Practice 12, 276-288.

Doran, J., J. Declan, and O’L. Eoin (2012). “The Effects of Frequency of Spatially Proximate and Distant Interaction on Innovation by Irish SMEs," Entrepreneurship \& Regional Development 24(7-8), 705-727.

Findikoglu, M.N., and M.B. Watson-Manheim (2015). "Do Small and Medium-Sized IT Firms Form Service Partnerships with Nonlocal IT Firms? An Assessment of Facilitators," Journal of Small Business Management 53(4), 986-1010.

Fisher, G. (2012). "Effectuation, Causation, and Bricolage: A Behavioural Comparison of Emerging Theories in Entrepreneurship Research,” Entrepreneurship Theory and Practice 36(5), 1019-1051. 
Flora, J. L., J. Sharp, and C. Flora (1997). "Entrepreneurial Social Infra-structure and Locally Initiated Economic Development in the Non -Metropolitan United States," The Sociological Quarterly 38(4), 623-645.

Foss, K., and N. J. Foss (2000). “The Knowledge-based Approach and Organisational Economics: How much do they really differ? And how does it Matter?” in Competence, Governance, and Entrepreneurship: Advances in Economic Strategy Research. Eds. N. Foss and V. Mahke. New York: Oxford University Press, 55-79. Foss, N.J. (1999). “Networks, Capabilities, and Competitive Advantage,” Scandinavian Journal of Management 14(3), 1-15.

Giuliani, E. (2005). “Cluster Absorptive Capacity: Why Do Some Clusters Forge Ahead and Others Lag Behind?," European Urban and Regional Studies 12(3), 269-288.

Global Group (2017). New Creative Work Space Opens in Bournemouth. [Online] Available at https://www.discoverglobal.co.uk/new-creative-workspace-opensbournemouth/ [Accessed on 14 July 2018]

Gordon, I., and P. McCan (2005). "Innovation, Agglomeration, and Regional Development," Journal of Economic Geography 5(5), 523-543.

Grabher, G. (2002). "Cool projects, boring institutions: temporary collaboration in social context," Regional Studies 36(3), 205-214.

Grant, R., M. (1996). “Towards a Knowledge-based Theory of the Firm,” Strategic Management Journal 17(S2), 109-122

Grimpe, C., and U. Kaiser (2010). "Balancing Internal and External Knowledge: The Gains and Pains from R\&D Outsourcing," Journal of Management Studies 47(8), 14831509.

Hagedoorn, J., and N. Wang (2012). "Is there Complementarity or Substitutability Between Internal and External R\&D Strategies?” Research Policy 41, 1072-1083.

Han, J.K., N. Kim, and H. B. Kim (2001). "Entry barriers: A dull-, one-, or two-edged sword for incumbents? Unraveling the paradox from a contingency perspective," Journal of Marketing 65(1), 1-14.

Hansen, T. (2015). "Substitution o Overlap? The Relations between Geographical and Nonspatial Proximity Dimensions in Collaborative Innovation Projects," Regional Studies 49(10), 1672-1684.

Horowitz, W. A., and E. L. C. Lai (1996). "Patent Length and the Rate of Innovation," International Economic Review 37(4), 785-799.

Huergo, E., and J. Jaumandreu (2004). "How does probability of innovation change with firm 
age?," Small Business Economics 22(3), 193-207.

Hulsink, W., T. Elfring, and W. Stam (2009). The Locus of Innovation in Small and Medium

-Sized Firms: The Importance of Social Capital and Networking in Innovative

Entrepreneurship. Cheltenham: Edward Elgar Publishing Inc.

Jack, S. (2010). “Approaches to Studying Networks: Implications and Outcomes," Journal of Business Venturing (25), 120-137.

Jack, S., and A. Anderson (2002). "The effects of embeddedness on entrepreneurial process," Journal of Business Venturing 17(5), 467-487.

Julien, P. A. (2007). The Theory of Local Entrepreneurship in the Knowledge Economy. Cheltenham: Edward Elgar Publishing Limited.

Kessler, E. H., and A.K. Chakrabarti (1996). "Innovation speed: A conceptual model of context, antecedents, and outcomes," Academy of Management Review 21(4), 1143 1191.

Kleinknecht, A., and J.O.N. Reijnen (1991). "More evidence on the undercounting of small firm R\&D," Research Policy 20, 579-587.

Lambkin, M. (1988). “Order of entry and performance in new markets,” Strategic Management Journal 9(S1), 127-140.

Lasagni, A. (2012). "How Can External Relationships Enhance Innovation in SMEs? New Evidence for Europe,” Journal of Small Business Management 50(2), 310-339.

Leiponen, A., and J. Byma (2009). "If You Cannot Block, You Better Run: Small Firms, Cooperative Innovation, and Appropriation Strategies," Research Policy 38(9), 1478 1488.

Lepak, D.P., K.G. Smith, and M.S. Taylor (2007). "Value Creation and Value Capture: A Multi-level Perspective," Academy of Management Review 32(1), 180-194.

Levi-Straus, C. (1996). The Savage Mind. Chicago: University of Chicago Press.

Lokshin, B., A. van Gils, and E. Bauer (2009). "Crafting firm competencies to improve innovative performance," European Management Journal 27(3), 187-196.

Long. J. S., and J. Feese (2006). Regression Models for Categorical Dependent Variables Using Stata. 2nd edition. Texas: Stata Press.

Ortega-Argilés, R., M. Vivarelli, and P. Voigt (2009). "R\&D in SMEs: a paradox?" Small Business Economics 33(1), 3-11.

Malmberg, A., and P. Maskell (2002). "The elusive concept of localization economies: Towards a knowledge based theory of special clustering," Environment and Planning A 34, 429-449. 
Malmberg, A., and D. Power (2005). “(How) Do (Firms in) Clusters Create Knowledge?” Industry and Innovation 12(4), 409-431.

Maskell, P. (2001). "Towards a knowledge based theory of the geographical cluster," Industrial and Corporate Change 10, 921-943.

McFadyen, M. A., and C. J. Albert. (2004). "Social capital and knowledge creation: Diminishing returns of the number and strength of exchange relationships," Academy of Management Journal 47, 735-746.

McGrath, G. R. (1999). “Falling Forward: Real Options Reasoning and Entrepreneurial Failure," Academy of Management Review 24(1), 13-30.

Miller, D. J., and Z. J. Acs (2017). “The campus as entrepreneurial ecosystem: the University of Chicago," Small Business Economics 49(1), 75-95.

Miotti, L., and F. Sachwald (2003). "Co-operative R\&D: Why and With Whom? An Integrated Framework of Analysis," Research Policy 32(8), 1481-1499.

Miozzo, M., and D. P. Grimshaw (2006). Knowledge Intensive Business Services. Cheltenham: Edward Elgar.

Mothe, C., and T. Uyen Nguyen Thi (2010). "The link between non-technological innovations and technological innovation," European Journal of Innovation Management 13 (3): 313-332.

Musolesi, A., and J. P. Huiban (2010). "Innovation and productivity in knowledge intensive business services," Journal of Productivity Analysis 34(1), 63-81.

Nambisan, S., and M. Sawhney (2011). "Orchestration Processes in Network-Centric Innovation: Evidence from the Field," Academy of Management Perspectives 25(3), $40-57$.

Nelson, R. R., and S. G. Winter, S.G (1982). An Evolutionary Theory of Economic Change. Cambridge: Harvard University Press.

Norton, E.C., A. Arbor, M. M. Miller, and L. C. Kleinman (2013). “Computing adjusted risk ratios and risk differences in Stata," Stata Journal 13(3), 492-509.

Ocasio, W. (1997). "Towards an Attention Based View of the Firm," Strategic Management Journal 18(51), 187-206.

Passiante, G., V. Elia, and T. Massari (2003). Digital Innovation: Innovation Process in Virtual Clusters and Digital Regions. London: Imperial College Press.

Paulson G., A. Kathy, S. A. Slotnick, and M. J. Sobel (2002). "New Product Innovation with Multiple Features and Technology Constraints," Management Science 48(10), 12681284. 
Peneder, M. (2001). Entrepreneurial competition and industrial location: investigating the structural patterns and intangible sources of competitive performance. Cheltenham: Edward Elgar Publishing Limited.

Pittaway, L., M. Robertson, K. Munir, D. Denyer, and A. Neely (2004). "Networking and Innovation: A Systematic Review of the Evidence," International Journal of Management Reviews 5/6 (3\&4), 137-168.

Podsakoff, P. M., and D. W. Organ (1986). "Self-reports in organizational research: Problems and prospects," Journal of Management 12(4), 69-82.

Pouder, R., and C. H. St. John (1996). "Hot Spots and Blind Spots: Geographical Clusters of Firms and Innovation,” Academy of Management Review 21(4), 1192-1225.

Powell, W.W., K.W. Koput, and L. Smith-Doerr (1996). "Inter-organisational collaboration and the locus of innovation: networks of learning in biotechnology," Administrative Science Quarterly 41(1), 116-145.

Presutti, M., C. Boari, and A. Majocchi (2011). "The Importance of Proximity for the StartUps' Knowledge Acquisition and Exploitation," Journal of Small Business Management 49(3), 361-389.

Putnam, R. (2000). Bowling Alone: The Collapse and Revival of American Community. New York: Simon \& Schuster.

Radicic, D., and G. Pugh (2017). "Performance Effects of External Search Strategies in European Small and Medium-Sized Enterprises," Journal of Small Business Management 55(S1), 76-114.

Radicic, D., G. Pugh, H. Hollanders, R. Wintjes, and J. Fairburn (2016). "The impact of innovation support programmes on SME innovation in traditional manufacturing industries: an evaluation for seven EU regions," Environment and Planning C: Government and Policy 34(8), 1425-1452.

Rae, D. (2017). “Entrepreneurial learning: peripherality and connectedness," International Journal of Entrepreneurial Behavior \& Research 23(3), 486-503.

Rickey, B., and J. Houghton (2009). "Solving the Riddle of the Sands: Regenerating England's Seaside Towns," Journal of Urban Regeneration and Renewal 3(1), 46-55. Robson, P. J. A., C. Akuetteh, P. Westhead, and M. Wright (2012). "Innovative Opportunity Pursuit, Human Capital and Business Ownership Experience in an Emerging Region: Evidence from Ghana," Small Business Economics 39(3), 603-625.

Rodrik, D., and A. Subramanian (2008). "The Primacy of Institutions (and What this Does and Does not Mean)," In The Development Economics Reader. Eds. G. Secondi. New York: 
Routledge, pp.79-85.

Singh, J. V., D. J. Tucker, and R. J. House (1986). "Organizational legitimacy and the liability of newness," Administrative science quarterly 31(2), 171-193.

Slade, D. (2016). 3d Printers, Laser Cutters, and Event Space: The New Lab Just for Start-up Businesses. [Online] Available at: http://www.bournemouthecho.co.uk/news/14188003.3D_printers_laser_cutters_and events_space the new_lab_just_for_start-up_businesses/[Accessed 14 July 2018]

Sonobe, T., J. Akoten, and K. Otsuka (2011). "The growth process of informal enterprises in

Sub-Saharan Africa: a case study of a metalworking cluster in Nairobi," Small Business Economics 36(3), 323-335.

Somaya, D., Williamson, I. O., and N. Lorinkova (2008). "Gone but not lost: The different Performance impacts of employee mobility between cooperators versus competitors," Academy of Management Journal 51(5), 936-995.

Sunley, P. (2008). "Relational Economic Geography: A Partial Understanding or a New Paradigm," Economic Geography 84(1), 1-26.

Sussan, F. and Z. J. Acs (2017). “The digital entrepreneurial ecosystem," Small Business Economics 49(1), 55-73

Tech Nation Report. (2015). "Powering the digital economy," Available online at: http://www.techcityuk.com/wp-content/uploads/2015/02/Tech\%20Nation\%202015.pdf [Accessed 10 December 2017].

Teirlinck, P. (2018). "Pathways for knowledge exchange in SMEs in software-driven knowledge-intensive business services," $R \& D$ Management 48(3), 343-353.

Thomas, B. (2011). "The Power of Combinative Capabilities: Facilitating the Outcome of Frequent Innovation in Pharmaceutical R\&D Projects," Project Management Journal $42(2), 63-80$.

Tidd, J., and J. Bessant (2009). Managing Innovation: Integrating Technological, Market and Organizational Change. Chichester: Wiley.

Un, C. A., and A. Montoro-Sanchez (2010). "Innovative Capability Development for Entrepreneurship: A Theoretical Framework," Journal of Organisational Change 23(4), 413-434.

Un, C.A, Cuervo-Cazurra, A. and K. Asakawa (2010). "R\&D Collaborations and Product Innovation," Journal of Product Innovation Management 27, 673-389.

Valliere, D., and T. Gegenhuber (2014). "Entrepreneurial Remixing: Bricolage and Postmodern Resources," Entrepreneurship and Innovation 15(1), 5-15. Van de Ven. H.A. (1986). "Central Problems in the Management of Innovation," 
Management Science 32(5), 590-607.

Vaona, A., and M. Pianta (2008). "Firm size and innovation in European manufacturing," Small Business Economics 30(3), 283-299.

Varesca, V., Jeroen, J., Wim, V., and R. Maurice (2009). “Open Innovation in SMEs: Trends, Motives, and Management Challenges," Technovation 29(6-7), 423-437.

Walker, G., B. Kogut, and W. Shan (1997). "Social Capital, Structural Holes and Formation of an Industry network," Organisation Science 8(2), 109-125.

Wang, C. L, and P. K. Ahmad (2007). "Dynamic Capabilities: A Review and Research Agenda," International Journal of Management Review 9(1), 31-51.

Wang, Z., and N. Wang (2012). "Knowledge sharing, innovation and firm performance," Expert Systems with Applications 39(10), 8899-8908.

Williams, R. (2006). “Generalized Ordered Logit/Partial Proportional Odds Models for Ordinal Dependent Variables,” Stata Journal 6(1), 58-82.

Wolfe, R., and W.W. Gould (1998). "sg76: An Approximate Likelihood-Ratio Test for Ordinal Response Models," Stata Technical Bulletin 42, 24-27 (reprinted in Stata Technical Bulletin Reprints 7, 199-204. College Station,TX: Stata Press).

Yoshino, Y. (2011). Industrial Clusters and Micro and Small Enterprises in Africa: From Survival to Growth. Washington: The World Bank.

Zahra, S. A., Yavuz, R. I. and D. Ucbasaran (2006). "How Much Do You Trust Me? The Dark Side of Relational Trust in New Business Creation in Established Companies," Entrepreneurship Theory and Practice 30(4), 541-559.

Zook, M. A., and M. Graham (2007). "The creative reconstruction of the Internet: Google and the privatization of cyberspace and DigiPlace," Geoforum 38(6), 1322-1343. 


\section{Appendix}

\section{Table A1. The correlation matrix}

\begin{tabular}{|c|c|c|c|c|c|c|c|c|c|}
\hline & 1. & 2. & 3. & 4. & 5. & 6. & 7. & 8. & 9. \\
\hline $\begin{array}{l}\text { 1. Outbound- } \\
\text { temporary }\end{array}$ & 1.000 & & & & & & & & \\
\hline $\begin{array}{l}\text { 2. Outbound } \\
\text { prolonged }\end{array}$ & $0.473 * * *$ & 1.000 & & & & & & & \\
\hline $\begin{array}{l}\text { 3. Cognitive } \\
\text { proximity }\end{array}$ & -0.004 & 0.013 & 1.000 & & & & & & \\
\hline $\begin{array}{l}\text { 4. Geographical } \\
\text { proximity }\end{array}$ & 0.088 & -0.006 & $0.298 * * *$ & 1.000 & & & & & \\
\hline $\begin{array}{l}\text { 5. External } \\
\text { knowledge providers }\end{array}$ & $0.115^{*}$ & 0.102 & $0.128 * *$ & $0.233 * * *$ & 1.000 & & & & \\
\hline 6. Young & 0.033 & 0.070 & -0.006 & 0.013 & -0.055 & 1.000 & & & \\
\hline 7. Micro firms & $-0.131 * *$ & -0.028 & 0.028 & 0.009 & $-0.179 * * *$ & $0.344 * * *$ & 1.000 & & \\
\hline 8. Tertiary degree & 0.022 & -0.041 & $-0.250 * * *$ & -0.065 & $0.128 * *$ & 0.078 & -0.029 & 1.000 & \\
\hline $\begin{array}{l}\text { 9. Resources for } \\
\text { product innovation }\end{array}$ & $0.124 *$ & 0.031 & 0.089 & -0.066 & 0.099 & $-0.124 *$ & $-0.277 * * *$ & 0.061 & 1.000 \\
\hline
\end{tabular}

Notes: $* * * \mathrm{p}<0.01, * * \mathrm{p}<0.05, * \mathrm{p}<0.1$. 